\title{
Suggested Statistical Models for Analysis Non-stationary Time Series and Sudden Changes with Application on Stock Exchange Indices
}

\author{
Mostafa Ahmed Aly, Ahmed Fathy Abd Elaal Elwaqdy* \\ Department of Statistics, Mathematics and Insurance, Faculty of Commerce, Ain Shams University, Cairo, Egypt \\ Email address: \\ elwaqdy_ahmed75@yahoo.com (A. F. A. E. Elwaqdy) \\ ${ }^{*}$ Corresponding author \\ To cite this article: \\ Mostafa Ahmed Aly, Ahmed Fathy Abd Elaal Elwaqdy. Suggested Statistical Models for Analysis Non-stationary Time Series and Sudden \\ Changes with Application on Stock Exchange Indices. American Journal of Theoretical and Applied Statistics. \\ Vol. 9, No. 5, 2020, pp. 185-200. doi: 10.11648/j.ajtas.20200905.12
}

Received: August 8, 2020; Accepted: August 24, 2020; Published: September 14, 2020

\begin{abstract}
This study evaluates the performance of a group of GARCH models under three different distributions in terms of their ability to estimate and forecasting the volatility of Egyptian Stock Exchange General Index (EGX30) in some horizon of forecasting using daily data for the period from January 2, 2000 to April 30, 2019, and tries to determine the best model according to some criteria. The primary purpose of the study is to investigate whether the two-regime MSW-GARCH model outperforms the uni-regime GARCH models in a very volatile time period during the global financial crisis. Hence, evaluating the predictive accuracy of the MSW-GARCH, and whether the MSW-GARCH assessed on the EGX30 would be successful. We explore and compare different possible sources of forecasts improvements: asymmetry in the conditional variance, fattailed distributions and regime-switching methodology. The results show that; there is an evidence that the EGX30 index has been affected by the crisis, and the TGARCH models are superior in predictive ability on EGX30 compared to the other tested models. Consequently, uni-regime GARCH models has priority in MSW-GARCH models in their forecasting performance. These models yield significantly better out-of-sample volatility forecasts.
\end{abstract}

Keywords: Volatility, Structural Changes, Uni-regime GARCH Models, Two-regime MSW-GARCH Models, and Egyptian Stock Market

\section{Introduction}

Many important economic variables exhibit nonlinear behavior. The difficulty is to properly capture the form of the nonlinearity. Once the linear framework is abandoned, the specification problem must to be addressed. The use of an incorrect nonlinear specification may be worse than ignoring the nonlinearity. Moreover, a linear model can always be viewed as a local approximation of a nonlinear process [26].

One of the most prominent stylized facts of returns on financial assets is that their volatility changes over time. In particular, periods of large movements in prices alternate with periods during which prices hardly change. This characteristic feature commonly is referred to as volatility clustering [9]. This pattern may be reflected in big changes in returns of a day or few days followed by an opposite change in the following days. Because these groups of volatilities, the variance of financial time series changes over time and so the forecast periods of series levels also change over time, and the assumption of homoscedasticity is inappropriate and becomes obligatory for us to predict the conditional variance of the series. The general indicator data is a clear example of the time series with a time-dependent mean and an obviously appearance of heteroskedasticity.

In this study, we use (extensions of) the class of (Generalized) Autoregressive Conditional Heteroscedasticity ((G) ARCH) models, introduced by Engle and Bollerslev [6, 2].

When dealing with observations of time-dependent mean variables, GARCH models can be used. These also can 
describe some volatilities in conditional variance.

GARCH models are capable of describing not only the feature of volatility clustering, but also certain other characteristics of financial time series, such as their pronounced excess kurtosis or fat-tailedness. Most of nonlinear variants of the basic GARCH model designed to capture such aspects as the asymmetric effect of positive and negative shocks on volatility, and possible correlation between the return and volatility [9]. Given the widespread evidence of asymmetry in equity returns, positive and negative interest rate innovations may have markedly different impacts on the mean and/or variance of equity returns [15].

Unfortunately, GARCH models often do not hilly capture the thick tails property of high frequency financial times series. This has naturally led to the use of non-normal distributions to better model this excess kurtosis [22]. Adding non-normal densities is a promising area, as long as used with clearly non-normal series. Taking in consideration the excess kurtosis in high-frequency data, Student's $t$ and Generalized Error Distribution (GED) have become alternatives to the Normal distribution. Furthermore, a tdistribution instead of a normal one for the error term helps make the regimes more stable.

Another class of nonlinear models widely used in econometrics is the Markov Switching model (MSM) which was advocated by Hamilton [14]. A natural approach to modelling economic time series with nonlinear models seems to be to define different states of regimes, and to allow for the possibility that the dynamic behaviour of economic variables depends on the regime that occurs at any given point in time [23]. By 'state-dependent dynamic behaviour' of a time series it is meant that certain properties of the time series, such as its mean, variance and/or autocorrelation, are different in different regimes.

MSM is used in studies that require measuring the probabilities of moving (transformation) from one state to another, and the current state depends only on the previous state (according to Markov's theory). Thus, switching in the MSM is based on transition probabilities. In some sense, the switching is "stochastic" because it is governed by a probability law [27]. Hence, predictions using MSM tend to have higher uncertainty. Failure to account for regime switching may lead to invalid inference, biased forecasts and volatility estimates may be biased.

The two-regime MSW-GARCH model describes the two regimes of financial market returns situation as following two different distributions with a Full and complete identification of random operations and transition probabilities between these two distributions, which determine the possibility of estimating the required return.

There are several important features of using MSM can be summarized as follows [15, 26, 27]. First, it enables users to estimate both filtered and smoothed state probabilities. Second, the overall degree of persistence depends on the autoregressive parameters and the transition probabilities. Third, it allows for switching between regimes and time variation and asymmetry in the conditional variance within regime. Forth, it also allows for regime dependence in the impact, persistence and asymmetric response to shocks to equity volatility. Finally, it is flexible and can be useful in many applications.

However, since the transition probabilities are unknown, they need to be estimated along with the coefficients of the two autoregressive processes. If one of the regimes rarely occurs, the coefficients for that regime will be poorly estimated [26]. Furthermore, Since the state is not directly observable, it is a latent variable. Thus, MSM belongs to the statistical family of latent variables as such it requires heavier computation in estimation [27].

When financial returns exhibit sudden jumps that are due to structural breaks the GARCH models show high volatility persistence, i.e. integrated behaviour of the conditional variance. In such situations models in which the parameters are allowed to change over time are more appropriate.

We develop a Markov-switching GARCH model (MSWGARCH) wherein the conditional mean and variance switch in time from one GARCH process to another. This model enables to estimate complex functional GARCH specifications within each regime and features time-varying transition probabilities. It outperforms uni-regime GARCH models in forecasting volatility when sudden switching occurs in response to financial crisis [1].

MSW-GARCH model can remove the high persistence of GARCH model and separately in each regime of volatility [19]. The estimation of the MSW-GARCH accurately describes the two regimes based on the different pattern of adjustment of the stock returns volatility; and captures all the events that are responsible for the presence of nonlinear features in stock returns [19]. Moreover, MSW-GARCH model improves on existing variants, by making multiperiod-ahead volatility forecasting a convenient recursive procedure [18]. Finally, this model makes better use of the conditioning information to integrate out the unobserved regimes, which translates into a better fit.

This study generalizes the GARCH model by distinguishing two regimes with different volatility levels; GARCH effects are allowed within each regime. It focusses on situations in which the regime process is stochastic. The study compares different GARCH models in terms of their ability to describe structural changes in returns caused by The global financial crisis 2008.

We consider six competing symmetric and asymmetric models to conduct forecasting of the stock returns volatility. These models are the estimated uni-regime GARCH models and MSW-GARCH model which enables to estimate functional GARCH specifications (GARCH, TGARCH and EGARCH specifically) within two regimes. By obtaining the 30-step 90-step, 180-step and 365-step ahead forecast for stock returns volatility for the out-of-sample period, we compare the out-of-sample performance of the competing models on the basis of forecasting accuracy.

The econometric estimations of uni-regime GARCH models (GARCH, CGARCH, EGARCH, TGARCH and 
PGARCH) are performed with EVIEWS. The remaining models (MSW-GARCH models) are estimated with R program.

\section{Aim of Study}

This study emphasizes the importance of volatility in this kind of data not only as a variable has an important mean but also as a necessary explanatory variable in understanding the behaviour of many variables in finance.

The study aims to explore the best models that help in studying and analyzing non-stationary time series and sudden changes in stock returns, and to identify the properties of these models. Moreover, it evaluates the accuracy of volatility forecast from a set of uni-regime GARCH models and the two-regime MSW-GARCH during the financial crisis of 2008. Finally, how to use these models to obtain forecasts of stock market indicators is more accurate considering the problem of non-stationarity of the time series mean and variance.

We investigate the volatility characteristics of EGX30 measured by fat tail, volatility clustering, and leverage effects, in order to explore a parsimonious model for it and predict its future performance.

\section{Scope and Limitations of the Study}

This study will be limited to the study of the stocks only as a tool of the capital market. The study will also provide a method of statistical analysis to study past movement of stock to predict future values.

The data set used in the study consists of returns of the EGX30 index daily closing prices obtained from Egyptian Stock Exchange, during the period from January 2, 2000 to April 30, 2019.

The data were divided into two sample periods: previous and subsequent to the global financial crisis on September 15, 2008 (Lehman Brothers bankruptcy declaration) ${ }^{1}$. This date was assumed as the turning point, where the impact of the global financial crisis on the Egyptian stock exchange is examined.

The study on the applied side adopted three sets of data, that is the entire daily data of the Egyptian Stock Exchange General Index (EGX30) and the previous and subsequent index data to the global financial crisis.

The daily data consists of the number of 4703, 2490 and 2578 , for three samples respectively, which include 4338, 2125,2213 in sample observations covering periods from January 2, 2000 to October 31, 2017, from January 2, 2000 to September 14, 2008 and from September 15, 2008 to October 31,2017 respectively for estimating.

This is in addition to the number of $30,90,180$ and 365 (working days) out of sample observations of daily data covering period from September 15, 2008 to March 10, 2010

\footnotetext{
${ }^{(1)}$ https://en.wikipedia.org/wiki/Financial_crisis_of_2007-08.
}

for previous index data to the global financial crisis and from November 1, 2017 to April 30, 2019 for the other two samples to ensure the quality of the proposed models for describing data and forecasting.

\section{Model Identification}

\subsection{Linear GARCH Models}

Linear GARCH models [9, 10] cannot capture asymmetric effects of positive and negative shocks. As the conditional variance depends only on the square of the shock, positive and negative shocks of the same magnitude have the same effect on the conditional volatility-that is, the sign of the shock is not important.

\subsubsection{Generalized ARCH (GARCH) Model}

To reduce the computational problems when estimating the parameters of the ARCH model, Bollerslev [2] suggested adding lagged conditional variances to it. the GARCH model of order $(1,1)$ is given by

$$
h_{t}=\omega+\alpha_{1} \varepsilon_{t-1}^{2}+\beta_{1} h_{t-1}
$$

To guarantee nonnegativeness of the conditional variance $h_{t}$ which mean $h_{1} \geq 0$, the parameters in this model should satisfy $\omega>0, \alpha_{1}>0$ and $\beta_{1} \geq 0$. The general $\operatorname{GARCH}(p, q)$ model is given by

$$
\begin{aligned}
h_{t} & =\omega+\sum_{i=1}^{q} \alpha_{i} \varepsilon_{t-i}^{2}+\sum_{i=1}^{p} \beta_{i} h_{t-i} \\
& =\omega+\alpha(L) \varepsilon_{t}^{2}+\beta(L) h_{t}
\end{aligned}
$$

where $\beta(L)=\beta_{1} L+\ldots . .+\beta_{p} L^{p}, \alpha(L)=\alpha_{1} L+\ldots . .+\alpha_{q} L^{q}$ $p>0, q \geq 0$

$$
L \varepsilon_{t}^{2}=\varepsilon_{t-1}^{2}, L^{q} \varepsilon_{t}^{2}=\varepsilon_{t-q}^{2} \text { and } L \text { back shift operator }
$$

Assuming that all the roots of $1-\beta(L)=0$ are outside the unit circle, the model can be rewritten as an infinite-order ARCH model

$$
h_{t}=\frac{\omega}{1-\beta(1)}+\frac{\alpha(L)}{1-\beta(L)} \varepsilon_{t}^{2}=\frac{\omega}{1-\beta_{1}-\ldots . \beta_{p}}+\sum_{i=1}^{\infty} \delta_{i} \varepsilon_{t-i}^{2}
$$

For nonnegativeness of the conditional variance it is required that all $\delta_{i}$ are nonnegative.

\subsubsection{Component GARCH Model (CGARCH)}

Ding and Granger [4] argue that the sample autocorrelation functions of squared returns initially decrease faster than exponentially, and that only at higher lags does the decrease become (much) slower. This pattern suggests that volatility may consist of several components, some of which have a strong effect on volatility in the short run but die out quite rapidly, while others may have a small but persistent effect. 
To formalize this notion, Ding and Granger [4] put forward the component GARCH model

$$
\begin{gathered}
h_{t}=\gamma h_{1, t}+(1-\gamma) h_{2, t}, \\
h_{1, t}=\alpha_{1} \varepsilon_{t-1}^{2}+\left(1-\alpha_{1}\right) h_{1, t-1}, \\
h_{2, t}=\omega+\alpha_{2} \varepsilon_{t-1}^{2}+\beta_{2} h_{2, t-1}
\end{gathered}
$$

In this model, the conditional variance is seen to be a weighted sum of two components, one specified as an IGARCH model and the other as a GARCH model [9].

\subsection{Nonlinear GARCH Models}

Positive and negative shocks may have an asymmetric impact on the conditional volatility of subsequent observations. That is, the effect of signs can have the greatest impact on market returns.

In this section we review some of nonlinear GARCH models $[9,10]$. Most nonlinear GARCH models are motivated by the desire to capture the different effects of positive and negative shocks on conditional volatility or other types of asymmetry.

With respect to the specification of nonlinear GARCH models, it seems reasonable to start with specifying and estimating a linear GARCH model. We may then move on to a nonlinear GARCH model only if certain misspecification tests suggest that symmetry of the conditional variance function is an untenable assumption [10].

A convenient way to compare different GARCH models is by means of the so-called news impact curve (NIC), introduced by Pagan \& Schwert [21] and popularized by Engle and $\mathrm{Ng}$ [7]. The NIC shows the relationship between the current shock or news $\varepsilon_{t}$ and conditional volatility 1 period ahead $h_{t+1}$, holding constant all other past and current information. Thus, the NIC for the GARCH $(1,1)$ model is defined as

$$
\operatorname{NIC}\left(\varepsilon_{t} \mid h_{t}=h\right)=\omega+\alpha_{1} \varepsilon_{t}^{2}+\beta_{1} h=A+\alpha_{1} \varepsilon_{t}^{2}
$$

where $A=\omega+\beta_{1} h$. Hence, the NIC is a quadratic function centred on $\varepsilon_{t}=0$.

\subsubsection{GJR_GARCH (TGARCH)}

A weakness of the GARCH models is that they do not distinguish past negative returns from the positive ones. On the other hand, large past negative returns tend to have a greater impact on the volatility than their positive counterparts. This is known as the leverage effect in finance. To overcome this weakness, the threshold GARCH (TGARCH) or GJR models have been proposed. The parameter $\gamma$ is referred to as the leverage effect and it is expected to be positive. The estimated leverage effect is statistically significant at the 5\% level [27].

This model introduced by Glosten et al. [11] offers a method to allow for asymmetric effects of positive and negative shocks on volatility. The model is obtained from the GARCH $(1,1)$, Equation (1), by assuming that the parameter of $\varepsilon_{t-1}^{2}$ depends on the sign of the shock, that is,

$$
h_{t}=\omega+\alpha_{1} \varepsilon_{t-1}^{2}\left(1-I\left[\varepsilon_{t-1}>0\right]\right)+\gamma_{1} \varepsilon_{t-1}^{2} I\left[\varepsilon_{t-1}>0\right]+\beta_{1} h_{t-1}
$$

where as usual $I[$.$] is an indicator function. The conditions$ for nonnegativeness of the conditional variance are $\omega>0,\left(\alpha_{1}+\gamma_{1}\right) / 2 \geq 0$ and $\beta_{1}>0$. The condition for covariance-stationarity is $\left(\alpha_{1}+\gamma_{1}\right) / 2+\beta_{1}<1$. If this condition is satisfied, the unconditional variance of $\varepsilon_{t}$ is $\sigma^{2}=\omega /\left(1-\left(\alpha_{1}+\gamma_{1}\right) / 2-\beta_{1}\right)$.

The NIC for the GJR-GARCH model follows directly from Equation (6) and is equal to

$$
\begin{gathered}
N I C\left(\varepsilon_{t} \mid h_{t}=\sigma^{2}\right)=A+\alpha_{1} \varepsilon_{t}^{2} \text { if } \varepsilon_{t}<0 \\
\gamma_{1} \varepsilon_{t}^{2} \text { if } \varepsilon_{t}>0
\end{gathered}
$$

where $A=\omega+\beta_{1} \sigma^{2}$. The NIC of the TGARCH model is a quadratic function centred on $\varepsilon_{t}=0$, similar to the NIC of the basic GARCH model. However, the slopes of the TGARCH NIC are allowed to be different for positive and negative shocks.

\subsubsection{Exponential GARCH (EGARCH)}

Another commonly used volatility model with leverage effect is the exponential GARCH (or EGARCH) model of Nelson $[20,27]$. The EGARCH $(1,1)$ model is given by

$$
\ln \left(h_{t}\right)=\omega+\alpha_{1} z_{t-1}+\gamma_{1}\left(\left|z_{t-1}\right|-\mathrm{E}\left(\left|z_{t-1}\right|\right)\right)+\beta_{1} \ln \left(h_{t-1}\right)
$$

where $Z_{t}=\frac{\varepsilon_{t}}{\sigma_{t}}$

From Equation (8), we see that the coefficients of $Z_{t-1}$ are $\left(\alpha_{1}+\gamma_{1}\right)$ and $\left(\alpha_{1}-\gamma_{1}\right)$, respectively, for positive and negative $Z_{t-1}$. Taking into consideration the sign of $Z_{t-1}, \alpha_{1}$ draws the difference between positive and negative $Z_{t-1}$. Therefore, $\alpha_{1}$ of Equation (8) is called the leverage parameter [27].

As the EGARCH, Equation (8), describes the relation between past shocks and the logarithm of the conditional variance, no restrictions on the parameters $\alpha_{1}, \gamma_{1}$ and $\beta_{1}$ have to be imposed to ensure that $h_{t}$ is nonnegative. The NIC for the EGARCH (1,1), Equation (8), is given by

$$
\begin{gathered}
N I C\left(\varepsilon_{t} \mid h_{t}=\sigma^{2}\right)=A \exp \left(\frac{\alpha_{1}+\gamma_{1}}{\sigma} \varepsilon_{t}\right) \text { for } \varepsilon_{t}>0 \\
A \exp \left(\frac{\alpha_{1}-\gamma_{1}}{\sigma} \varepsilon_{t}\right) \text { for } \varepsilon_{t}<0
\end{gathered}
$$


with $A=\sigma^{2 \beta_{1}} \exp \left(\omega-\gamma_{1} \sqrt{2 / \pi}\right)$

The EGARCH model captures asymmetric effects in the data. It also provides the best description and a parsimonious representation in stock return modeling.

In the case of leverage effect is statistically significant, the decrease in the share price will have a greater impact on the subsequent volatility than the rise in the share price of the same size. Hence, we can expect that negative shocks have a larger effect on the conditional variance than positive shocks.

\subsubsection{Power GARCH Model (PGARCH)}

Taylor [25] and Schwert [24] introduced the standard deviation GARCH model, where the standard deviation is modeled rather than the variance. This model, along with several other models, is generalized in Ding et al. [5] with the Power ARCH specification. In the Power ARCH model, the power parameter $\delta$ of the standard deviation can be estimated rather than imposed, and the optional $\gamma$ parameters are added to capture asymmetry of up to order $r$ :

$$
\sigma_{t}^{\vartheta}=\omega+\sum_{j=1}^{q} \beta_{j} \sigma_{t-j}^{\vartheta}+\sum_{i=1}^{p} \alpha_{i}\left(\left|\varepsilon_{t-i}\right|-\gamma_{i} \varepsilon_{t-i}\right)^{\vartheta}
$$

where $\omega>0, \vartheta>0, \alpha_{\mathrm{i}} \geq 0, \beta_{\mathrm{i}} \geq 0,\left|\gamma_{\mathrm{i}}\right| \leq 1$ for $\mathrm{i}=1, \ldots, \mathrm{p}, \gamma_{i}=0$ for all $i>\mathrm{r}$, and $\mathrm{r} \leq \mathrm{p}$.

\subsubsection{Markov-Switching GARCH}

In the previous specifications, the parameters in the model change according to the sign and/or the size of the lagged shock $\mathcal{E}_{t-1}$. Therefore, these models can be interpreted as regime-switching models where the regime is determined by an observable variable, similar in spirit to the SETAR and STAR models for the conditional mean.

An obvious alternative is to assume that the regime is determined by an unobservable Markov-process $s_{t}$, as in the Markov-Switching model. A general Markov-Switching GARCH [MSW-GARCH] model is given by

$$
h_{t}=\left[\omega+\alpha_{1} \varepsilon_{t-1}^{2}+\beta_{1} h_{t-1}\right] I\left[s_{t}=1\right]+\left[\zeta+\gamma_{1} \varepsilon_{t-1}^{2}+\delta_{1} h_{t-1}\right] I\left[s_{t}=2\right]
$$

where $s_{t}$ is a two-state Markov chain with transition probabilities. The general form in Equation (11) is considered by Klaassen [17].

\section{Applied Study}

This study will be conducted on the daily data of the Egyptian Stock Exchange General Index EGX30 and the previous and subsequent index data to the global financial crisis.

We compare the forecasting performance of several GARCH-type models under three different distributional assumptions, namely the normal, student's $t$ and the GED- distribution $^{2}$.

\subsection{GARCH Models}

\subsubsection{Model Description}

A quick study of descriptive statistics for index EGX30 according to Table 1, the most important can be seen below:

Table 1. Descriptive Statistics.

\begin{tabular}{ll}
\hline & EGX30 \\
\hline Mean & 5377.715 \\
Median & 5620.355 \\
Maximum & 14342.38 \\
Minimum & 445.53 \\
Std. Dev. & 3492.094 \\
Skewness & 0.229673 \\
Kurtosis & 2.449604 \\
Jarque-Bera & 92.89359 \\
Probability & 0.0000 \\
Observations & 4338 \\
\hline
\end{tabular}

There are abnormal or extreme values but small percentage (not significant). By testing the presence of outliers, and noting the Box-plot shown in Figure 1, it appears that the time series has no outliers.

The distribution is positive skew indicates that the tail is on the right (the curve is bent to the right).

The curve has also a flat top means that the variables have a platykurtic (Excess kurtosis) distribution. Thus, the use of Student's $t$ distribution is more appropriate to capture the fat tail in the time series and better estimate the data.

Given the Jarque-Bera statistic [16], we reject the null hypothesis that series data follow normal distribution.

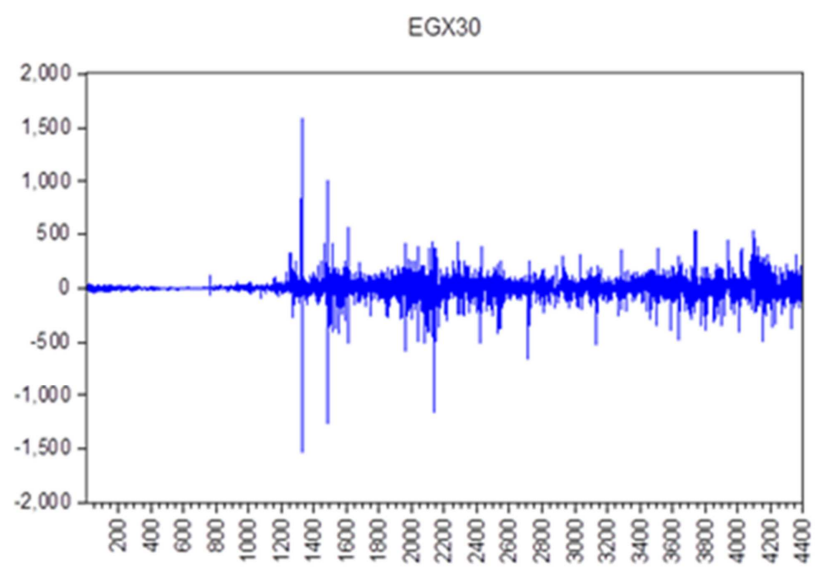

Figure. 2. Time series after deleting the general trend.

It is clear from examination of the linear graph for daily time series at Figure 1, a general trend apparent in series which indicates the arithmetic mean instability. As can be seen when we examine the autocorrelation function ACF and partial autocorrelation function PACF in the graph of "Correlogram", which need to take successive differences in

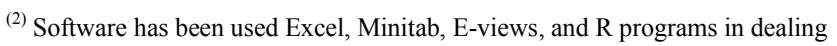
with the data.
} 
trying to get stationary in mean.
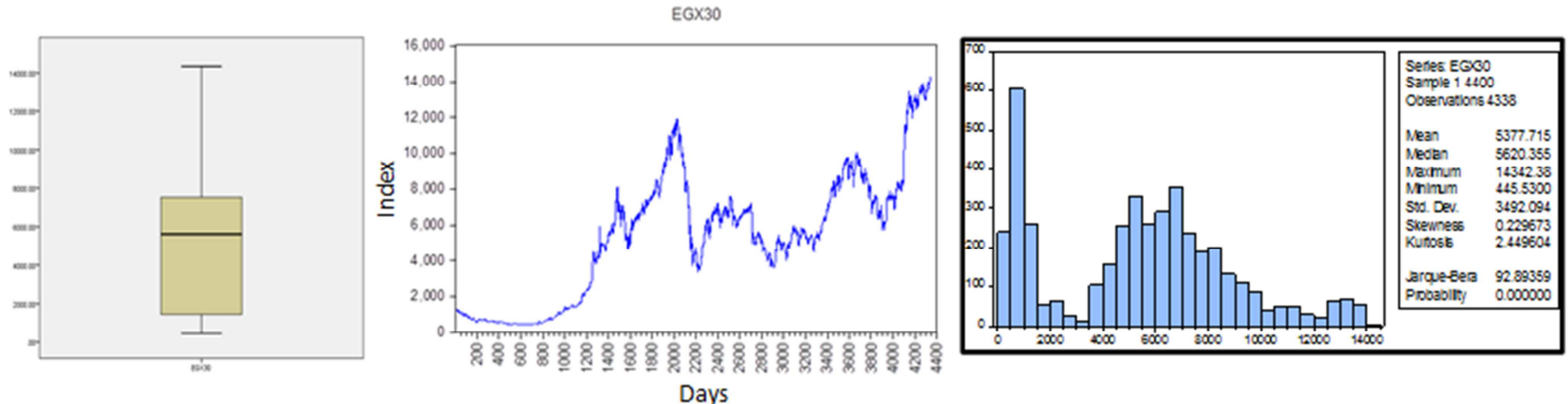

Figure 1. Box-Plot and Linear Graph for daily time series.

As the value of the Augmented Dickey-Fuller test (ADF) [3] is 0.073 also the value of $\mathrm{P}$-value is 0.9637 which greater than $5 \%$. Thus, accept the null hypothesis that unit root test confirms the need to take successive differences to get stationary in series. Also the instability of variations over the series that show from different fluctuations which appears clearly after deleting the general trend by taking the first difference of the series as shown in Figure 2.

Therefore, we find that it has to make the analysis of daily data series to so-called returns series for stable time series. A return series takes the following form:

$$
r_{t}=\ln \left(p_{t+1} / p_{t}\right)=\ln p_{t+1}-\ln p_{t}
$$

where $p_{t}$ and $p_{t+1}$ denote the successive observations of the general index at time $t$ and time $t+1$, respectively.

The following Figure 3 show the linear graph of the return series. Contrast of Figure 2, we find that the conversion of the general index to returns produced stationary time series.

When we examine the ACF and PACF of the returns series, the coefficients of autocorrelation and partial autocorrelation absent after the first time gap that mean they are significant at only the first gap.

As P-value of the statistic test Dickey-fuller equal to 0.000 . Therefore, reject the null hypothesis that the unit root test confirms the returns series appear stable. This is strong evidence supports that ARIMA $(0,1,0)$ suitable for time series and we can begin to estimate the parameters of the model AR (p) and MA (q).

We repeat the same procedures and Previous tests on the previous and subsequent index data to the global financial crisis (Before \& After).

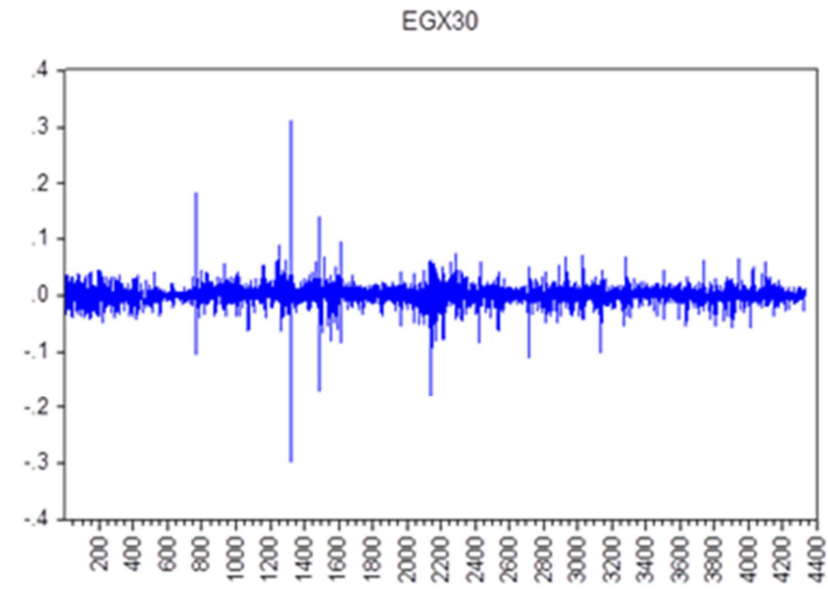

Figure 3. Linear Graph of the return series.

\subsubsection{Estimation of ARIMA Model Parameters}

We make several attempts to estimate a suitable ARIMA model-after excluding models that contain insignificant parameters, and note that these models are covered up to AR (3) and MA (3) for both model parameters.

The best model for the three periods was chosen based on the following selection criteria; information criterion AIC, S. E. of regression (SEE), Adjusted R-squared and Log likelihood. Correlogram-Q-statistics should show that there is no significant pattern left in the ACFs and PACFs of the residuals, it means the residuals of the selected model are white noise.

According to statistical results, models ARIMA $(2,1,3)$, ARIMA $(3,1,3)$ and ARIMA $(2,1,1)$ have the four previous terms as shown in Table 2.

Table 2. The best ARIMA models.

\begin{tabular}{llllll}
\hline & ARIMA Models & Akaike & Adjusted R-squared & S. E. of regression & Log likelihood \\
\hline EGX30 & ARIMA $(2,1,3)$ & -5.102557 & 0.010331 & 0.018856 & 11065.79 \\
Before & ARIMA $(3,1,3)$ & -4.964508 & 0.010684 & 0.020185 & 5271.861 \\
After & ARIMA $(2,1,1)$ & -5.301409 & 0.047722 & 0.017068 & 5862.057 \\
\hline
\end{tabular}

Appendix, Table A1 contains the results of the previous estimated models for return series.

\subsubsection{Diagnostic Tests of Proposed Models}

By reference to Appendix, Table A1, note that the parameters of all models at the level of $1 \%$ significance. As can be seen from the Figure 4 that the roots of parameters in case of characterize ARIMA models approaching the unit 
circle $^{3}$.

First: Serial Correlation tests [3]:

Representation Correlogram square residual or Correlogram-Q-statistics:

We note that all the autocorrelation coefficients and partial autocorrelation coefficients of the residuals fall within the confidence limits. We also note that most of the values of Pvalue less than $5 \%$. Therefore, we reject the null hypothesis and accept the alternative hypothesis that these models have serial correlation.

Breusch-Godfrey Serial Correlation LM Test:

By running this test, we note that $\mathrm{P}$-value $<0.05$. Therefore, we reject the null hypothesis that there is no serial correlation in residuals which mean the estimated models have serial correlation.

Second: ARCH test (Heteroskedasticity Test: ARCH) [3]:

Before estimating a GARCH models, it is important also to run the Engle [6] test for the ARCH effect to make sure that this model is appropriate for the data.

By running this test, we note that $\mathrm{P}$-value $=0.000$, which means significant effect of remaining $\mathrm{ARCH}$ behaviour for the estimated models.

Third: Test of Normality:

By running this test and noting Jarque-Bera statistic as well as the value of P-value, we can reject the null hypothesis and accept the alternative hypothesis that the residuals do not follow the normal distribution.

Thus, according to these tests, the decision is reject the null hypothesis that the stability of variations is homoscedastic normal process and accept the alternative hypothesis that there is conditional variance heteroskedasticity. So we need to complete the analysis by estimating GARCH model of conditional variance.

Inverse Roots of AR/MA Polynomial(s)

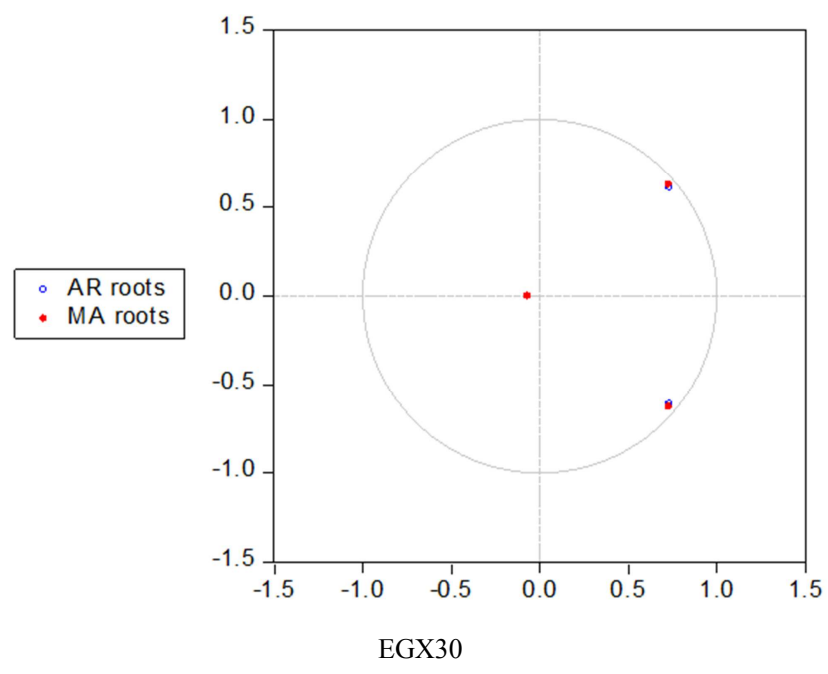

(3) Note that: The graph view plots the roots in the complex plane where the horizontal axis is the real part and the vertical axis is the imaginary part of each root. If the estimated ARMA process is stationary, then all AR roots should lie inside the unit circle. If the estimated ARMA process is invertible, then all MA roots should lie inside the unit circle [8].
Inverse Roots of AR/MA Polynomial(s)
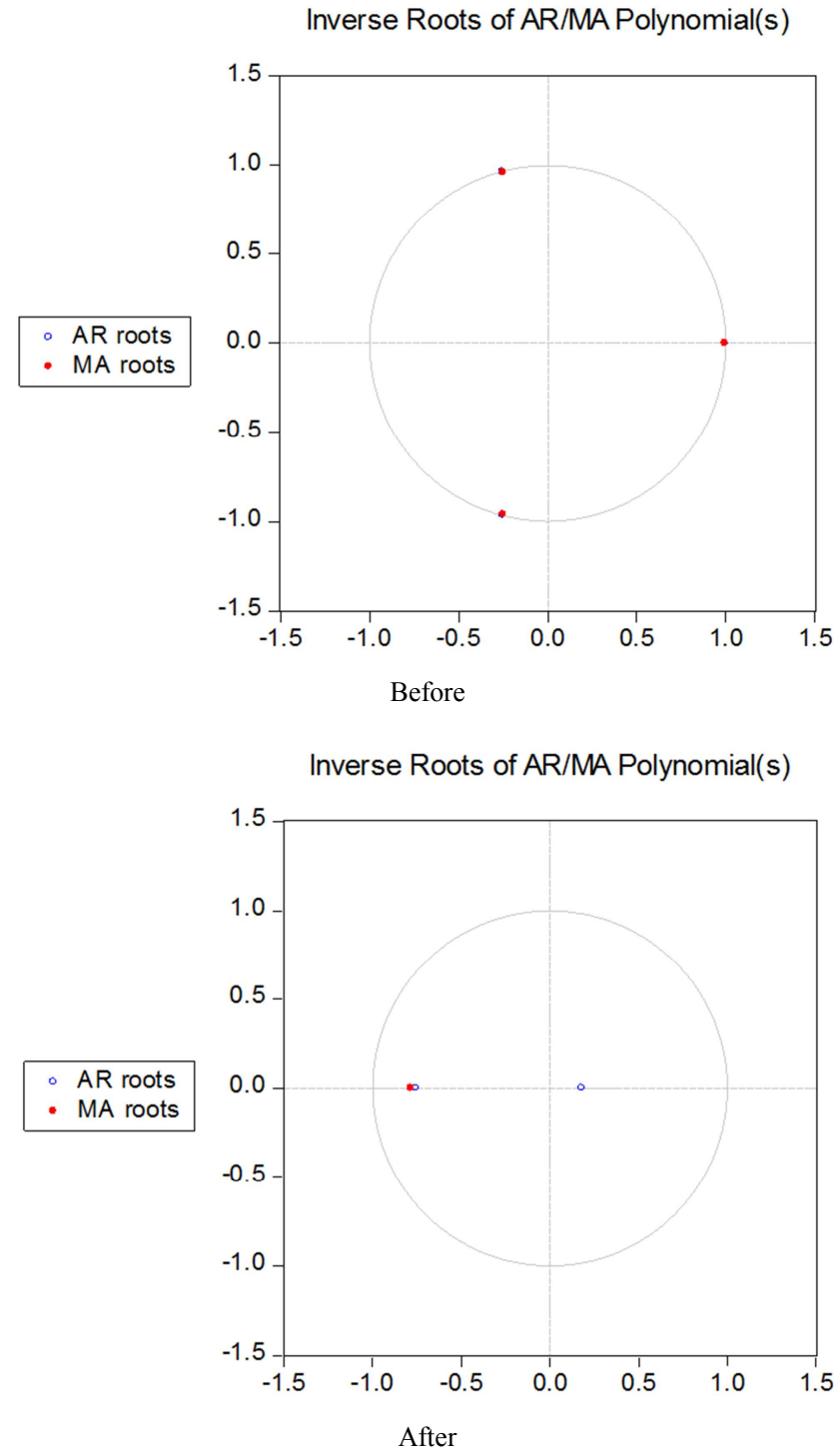

Figure 4. Graphs for the roots of parameters of ARIMA models.

\subsubsection{Study of the Variations of Estimating Models and Estimate Different forms of GARCH Models}

This study investigates the performance of six GARCHtype models to predict the volatility. They are; GARCH and CGARCH representing symmetric models, PGARCH, EGARCH, TGARCH and MSW-GARCH models representing asymmetric models, under three different distributional assumptions, namely the normal, student's $t$ and the GED-distribution. Noting that these models are covered up to the third order for both model parameters except for the MSW-GARCH models, which are covered with only the first order.

Estimate the suitable model orders by using information criterions:

To select the optimal GARCH model's orders, AIC criteria were used. GARCH model's orders should be chosen which minimum AIC value.

To reach appropriate GARCH models which follow the three distributions (normal, Student's $\mathrm{t}$ and GED), we analyzed results of estimating GARCH models based on 
ARIMA models description of conditional mean for daily data. Note that, these models must not violate non-negativity restriction on coefficients and all parameters must be significant.

\subsubsection{Diagnostic Tests of Estimated Models}

We conduct some diagnostic tests to ensure the integrity of the characterization of estimated models of daily returns which consists of: Correlogram square residual or Correlogram-Q-statistics and ARCH LM test.

Appendix, Table A2 Shows the final results of estimating GARCH models according to different distributions.

\subsubsection{Assess Forecast Models}

This section cares assess the performance of GARCH models that we estimated previously to predict volatility, to access the best one in terms of quality in the characterization and forecasting data. We will use four of the evaluation metrics to estimate the prediction accuracy [3] for observations out of sample to reach the finest model of their appropriate. These metrics are: Root Mean Square Error (RMSE), Mean Absolute Error (MAE), Mean Absolute Percentage Error (MAPE) and Theil's Inequality Coefficient (U).

Table 3 includes the best models for forecasting as a result of the predictions evaluation of volatility out-of-sample of the GARCH models which follows one of each distribution
(Normal, Student's t or GED) in some horizon of forecasting. Notes on Table 3:

For the entire EGX30 index data, the model ARIMA $(2,1,3)$-TGARCH $(1,1)$ GED demonstrated preference in short and long term (four periods ahead).

For the pre-crisis period, we note that the preference in forecasting has shifted from the model ARIMA $(3,1,3)$ EGARCH $(1,1)$ GED-which proved to be efficient in the short-term forecast up to 180 working days, to the model ARIMA $(3,1,3)$-TGARCH $(1,1) \mathrm{N}$-which has proven to be effective in the long-term forecast 365 working days. It is also worth noting that the ARIMA $(3,1,3)$-TGARCH $(1,1) \mathrm{N}$ is superior to the ARIMA $(3,1,3)$-EGARCH $(1,1)$ GED only in relation to the MAE over prediction periods. The two models will be considered when applying the Markov Switching GARCH model.

For the post-crisis period, the model ARIMA $(2,1,1)$ TGARCH $(1,1) \mathrm{N}$ has proven to be efficient in terms of its ability to describe structural changes in returns caused by The global financial crisis, as it demonstrated its preference in forecasting over a period of more than 30 working days.

As the kurtosis factor for data is close to the kurtosis factor for normal distribution, models which follow normal distribution can be chosen.

Table 3. The best GARCH models for forecasting.

\begin{tabular}{|c|c|c|c|c|c|c|}
\hline Range & Period & Model & MAE & RMSE & MAPE & $\mathbf{U}$ \\
\hline \multirow{4}{*}{ 30-step ahead } & the entire daily data & ARIMA $(2,1,3)$-TGARCH $(1,1)$ GED & 0.0068079 & 0.008365 & 117.21354 & 0.8475055 \\
\hline & \multirow{2}{*}{ before } & ARIMA $(3,1,3)$-EGARCH $(1,1)$ GED & 0.0389029 & 0.0519864 & 105.04435 & 0.7634604 \\
\hline & & ARIMA $(3,1,3)$-TGARCH $(1,1) \mathrm{N}$ & 0.0383618 & 0.0523441 & 162.43325 & 0.7687131 \\
\hline & after & ARIMA $(2,1,1)-$ GARCH $(1,1) \mathrm{N}$ & 0.0066709 & 0.0082397 & 129.28977 & 0.8348096 \\
\hline \multirow{4}{*}{90 -step ahead } & the entire daily data & ARIMA $(2,1,3)$-TGARCH $(1,1)$ GED & 0.003997 & 0.0062327 & 91.298786 & 0.8454707 \\
\hline & \multirow{2}{*}{ before } & ARIMA $(3,1,3)$-EGARCH $(1,1)$ GED & 0.0215264 & 0.0352633 & 66.613275 & 0.7809804 \\
\hline & & ARIMA $(3,1,3)$-TGARCH $(1,1) \mathrm{N}$ & 0.0211387 & 0.035355 & 88.867876 & 0.7830108 \\
\hline & after & $\operatorname{ARIMA}(2,1,1)-\mathrm{TGARCH}(1,1) \mathrm{N}$ & 0.0039354 & 0.0061937 & 91.062653 & 0.8401917 \\
\hline \multirow{4}{*}{$\begin{array}{l}\text { 180-step } \\
\text { ahead }\end{array}$} & the entire daily data & ARIMA $(2,1,3)$-TGARCH $(1,1)$ GED & 0.0019984 & 0.0044076 & 45.555742 & 0.8455549 \\
\hline & \multirow{2}{*}{ before } & ARIMA $(3,1,3)$-EGARCH $(1,1)$ GED & 0.0107218 & 0.0248775 & 33.626632 & 0.7791823 \\
\hline & & ARIMA $(3,1,3)-T G A R C H(1,1) \mathrm{N}$ & 0.0105806 & 0.0249439 & 43.306194 & 0.7812621 \\
\hline & after & $\operatorname{ARIMA}(2,1,1)-\operatorname{TGARCH}(1,1) \mathrm{N}$ & 0.0019674 & 0.004384 & 44.479202 & 0.8410373 \\
\hline \multirow{4}{*}{$\begin{array}{l}365 \text {-step } \\
\text { ahead }\end{array}$} & the entire daily data & ARIMA $(2,1,3)$-TGARCH $(1,1)$ GED & 0.0009837 & 0.0030927 & 22.373992 & 0.8448673 \\
\hline & \multirow{2}{*}{ before } & ARIMA $(3,1,3)-T G A R C H(1,1) \mathrm{N}$ & 0.0052302 & 0.0175224 & 21.594864 & 0.7815131 \\
\hline & & ARIMA $(3,1,3)$-EGARCH $(1,1)$ GED & 0.0052862 & 0.0175577 & 15.574084 & 0.7830887 \\
\hline & after & ARIMA $(2,1,1)-\operatorname{TGARCH}(1,1) \mathrm{N}$ & 0.0009687 & 0.0030768 & 21.966097 & 0.8405176 \\
\hline
\end{tabular}

\subsubsection{Chow Test}

A Chow test [12] was performed to determine whether the estimated model in the pre-crisis period could be applied on the post-crisis period.

The null hypothesis is $\mathrm{H}_{0}$ : there is no structural change (parameters are same for both subsamples), and the alternative hypothesis $\mathrm{H}_{1}$ : there is a structural change. The null hypothesis is rejected at $\mathrm{F}^{*}>\mathrm{F}_{\mathrm{c}}$.

We applied this test to the following models; The entire series model ARIMA $(2,1,3)$-TGARCH $(1,1)$ GED, the precrisis model ARIMA $(3,1,3)$-EGARCH $(1,1)$ GED, and the post-crisis model ARIMA $(2,1,1)-\operatorname{TGARCH}(1,1) \mathrm{N}$.
Conclusion: $\mathrm{F}^{*}=5.4592>\mathrm{Fc}=1.83=\Rightarrow$ reject $\mathrm{H}_{0}$. Meaning that there is a structural change in the sample (i.e. considering the specific date of the crisis in the study as a turning point). Consequently, the post-crisis model is the best to predict in the future, that is, ARIMA $(2,1,1)$-TGARCH $(1,1) \mathrm{N}$.

Figure 5 shows linear graphs of the estimated values for ARIMA $(3,1,3)$-EGARCH $(1,1)$ GED, and ARIMA $(2,1,1)-$ TGARCH $(1,1) \mathrm{N}$, and a turning point (Structural change):

Note that:

By comparing the accuracy of the models over the prediction periods based on the evaluation metrics (MAE, RMSE and MAPE), the two models; ARIMA $(2,1,3)$ - 
TGARCH $(1,1)$ GED and ARIMA $(2,1,1)-T G A R C H(1,1) \mathrm{N}$ are the best for forecasting.

By comparing the accuracy of the predicted model for the entire series with the another for the post-crisis series over the forecasting periods Table 3 , we note that the post-crisis model is the best.

According to Chow Test, it is possible to confirm the validity of what we have mentioned, Item No. 2 at notes on Table 3, that the preference in forecasting has shifted to the model ARIMA $(3,1,3)$-TGARCH $(1,1) \mathrm{N}$-which proved to be efficient in predicting over 365 working days.

The following Figure 6 shows predictive values with real values in some horizon of forecasting (Out of sample).
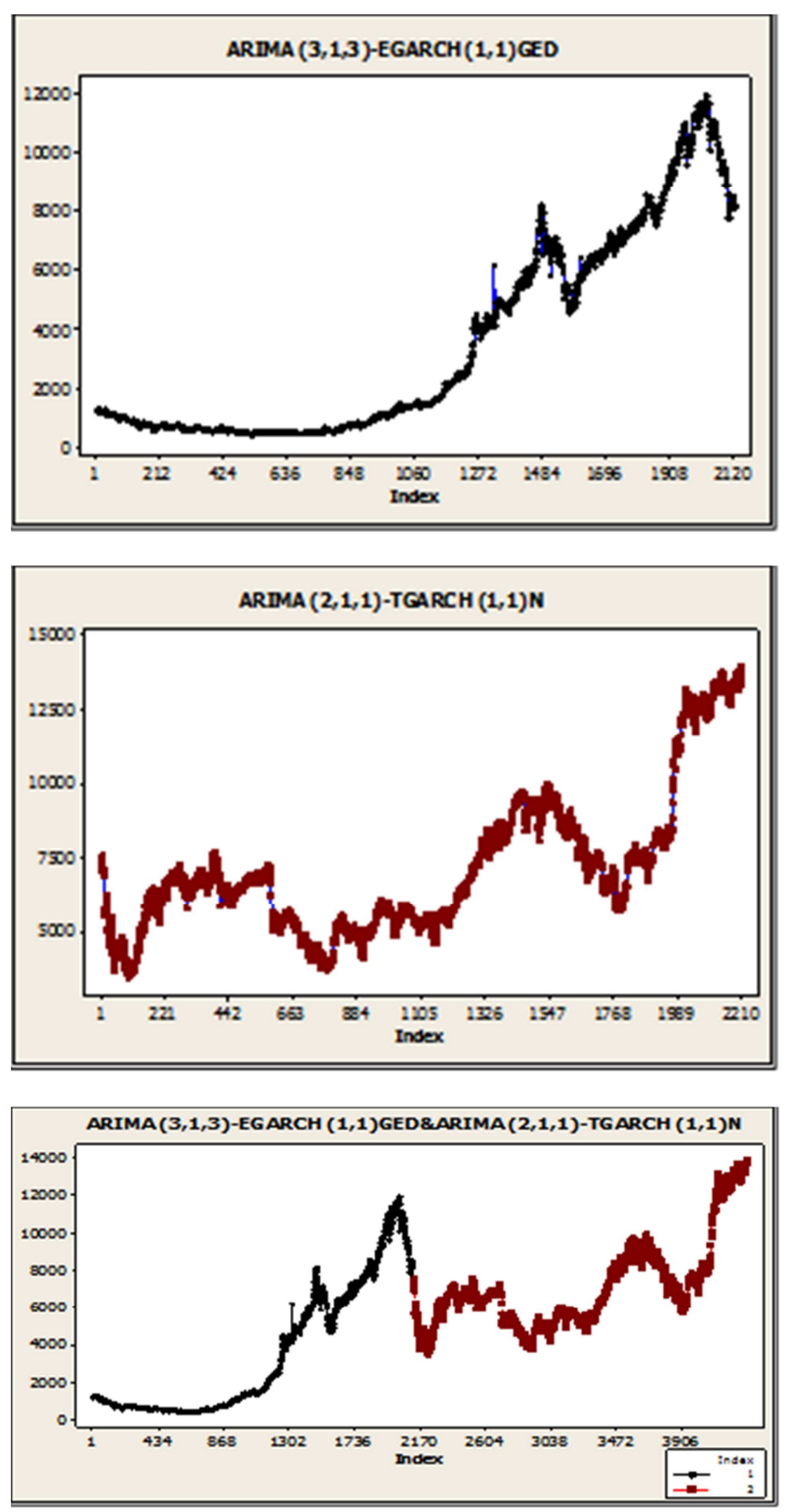

Figure 5. Linear Graphs for the two pre-and post-crisis periods and a turning point
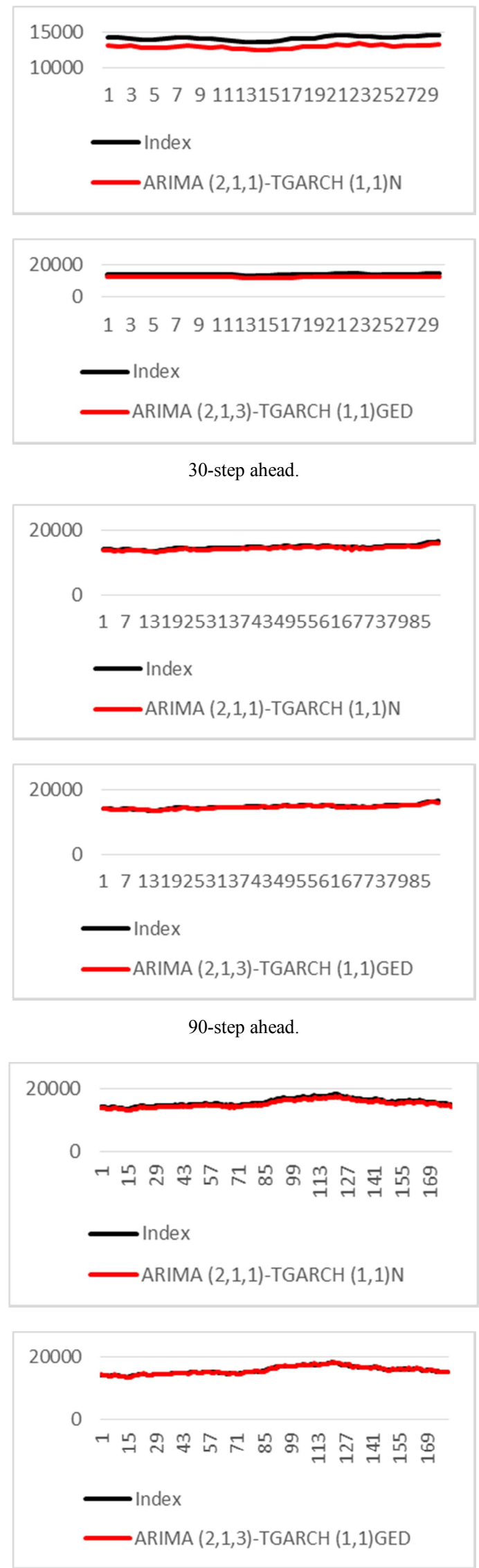

180 -step ahead. 

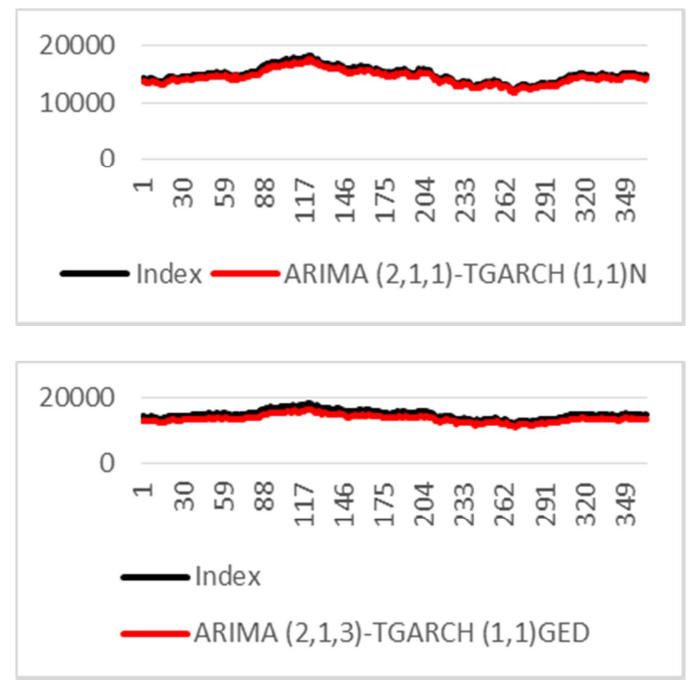

365-step ahead.

Figure 6. Predictive values with Real values in some horizon of forecasting.

Experimental Results

It proved the advantage of the normal and GED distribution, as it also proved that the EGX30 was affected by the crisis.

According to the Table 3 and Figure 6 we can conclude that the models ARIMA $(2,1,3)$-TGARCH $(1,1)$ and ARIMA $(3,1,3)$-EGARCH $(1,1)$ which follow GED distribution and ARIMA (2,1,1)-TGARCH $(1,1)$ which follows normal distribution are the best models which can provide more accurate predictions and descriptions of data.

By comparing the prediction accuracy of the two estimated models for both the entire and post-crisis series as well as according to the Chow test, we can conclude that the model ARIMA (2,1,1)-TGARCH $(1,1)$ which follows normal distribution best describes the volatility of daily returns.

Dependency of model estimates to normal distribution can be consistent as a result, due to the distribution of series data close to the kurtosis coefficient of normal distribution.

\subsection{Markov Switching GARCH}

In this section, we develop Markov-switching GARCH model which enables us to model GARCH equations for different functional forms $(\mathrm{GARCH}, \mathrm{TGARCH}$ and EGARCH Specifically) within two Markov-regimes.

Markov Switching GARCH models were estimated using Maximum-likelihood [13]. According to the results above, the preference of Markov Switching GARCH models will be tested in some horizon of forecasting with these assumptions:

The model TGARCH $(1,1)$ GED in both regimes, based on its preference to predict taking into account the entire series data.

Two models; EGARCH $(1,1)$ GED in the first regime and TGARCH $(1,1) \mathrm{N}$ in the second, based on the preference of the first for predicting the pre-crisis period and the second for predicting the post-crisis period.

The model TGARCH $(1,1) \mathrm{N}$ in both regimes, based on what the study concluded after proving The presence of structural change and transformation (turning) after the date of the crisis.

Our findings indicated the validity of the estimated Markov Switching model with the second assumption to describe the data and forecast only at P-value $>0.079$ for the parameter $\alpha_{22}$, and the invalidity of the other two assumptions due to insignificance some of their parameters.

Appendix, Table A3 shows the estimates results for the Markov Switching model assuming EGARCH $(1,1)$ GED in the first regime and TGARCH $(1,1) \mathrm{N}$ in the second.

Note that the parameter $\alpha_{22}$ is only significant at Pvalue $>0.079$, and we suggest completing the study.

Figure 7 shows the volatility curve for the estimated model:

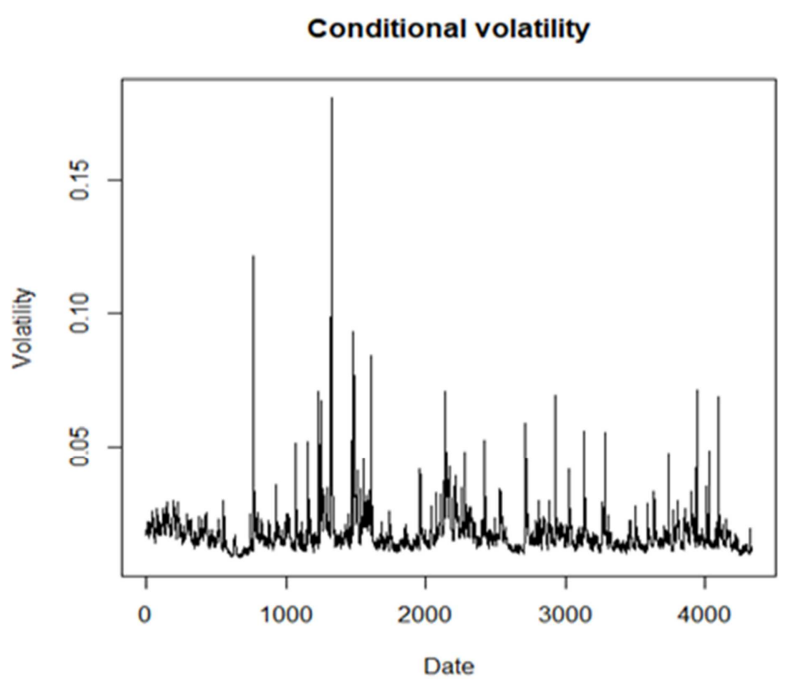

Figure 7. Conditional volatility for the estimated model.

The following Table 4 shows the prediction accuracy for the model over different periods ahead:

Table 4. The prediction accuracy for MSW-GARCH model.

\begin{tabular}{llll}
\hline Range & MAE & RMSE & MAPE \\
\hline 30-step ahead & 0.01682692 & 0.01866172 & 97.90138 \\
90-step ahead & 0.0171199 & 0.0189789 & 92.13989 \\
180-step ahead & 0.01895995 & 0.02114778 & 98.85186 \\
365-step ahead & 0.01952385 & 0.02200297 & 100.2956 \\
\hline
\end{tabular}

From Table 4 we can notice that the estimated model demonstrated an ability to produce relatively accurate shortterm forecasts of EGX30's volatility.

By comparing the prediction accuracy of this model with the model ARIMA $(2,1,1)$-TGARCH $(1,1) \mathrm{N}$ in Tables 3 and 4, Consequently, Markov Switching model, assuming EGARCH $(1,1)$ GED in the first regime and TGARCH $(1,1)$ $\mathrm{N}$ in the second did not gain an advantage over the estimated uni-regime GARCH models. Thus, uni-regime GARCH yields significantly better volatility forecasts than regimeswitching GARCH.

\section{Conclusion}

This study evaluates the forecast accuracy of some specific 
GARCH-models; GARCH, CGARCH, EGARCH, TGARCH, PGARCH and MSW-GARCH. The forecast horizon was 30, 90, 180 and 365 working days ahead. All models were estimated under three distributional assumptions, i.e., normal-, t-and GED-distribution. The study was performed on the entire data in addition to the two divided sample periods (previous and subsequent to the global financial crisis on September 15, 2008).

Our results suggest that improvements of the overall estimation are achieved when asymmetric GARCH are used and when fat-tailed densities are taken into account in the conditional variance. Moreover, it is found that TGARCH and EGARCH give better forecasts than symmetric GARCH.

With respect to the asymmetric reaction of the predicted volatility to good and bad news, our results also suggest that; for the two entire and post-crisis period, we find there is an adverse asymmetric reaction with good news increasing the volatility more than bad news but for the pre-crisis period, it confirm the absence of leverage effect.

According to the empirical application, Non-normal distributions provide better in-sample results than the Normal distribution. Out-of-sample results show however less evidence of superior forecasting ability.

Given Chow test, there is a structural change.
Consequently, the EGX30 was affected by the crisis.

Finally, the result shows that the uni-regime GARCH models are superior in predictive ability on EGX30 compared to the regime-switching GARCH models. And based on the forecast horizon in the sample outside the study, the postcrisis model ARIMA $(2,1,1)$-TGARCH $(1,1) \mathrm{N}$ is chosen as the best prediction model.

A natural line of future research could be the extension of our framework to more than two Markov-regimes. Other estimation procedures than ML approach may be implemented, for example Bayesian Markov Chain Monte Carlo (MCMC) algorithms which have the potential to provide an alternative way of circumventing the problem of path dependence. More research can also be done about identifying transition probabilities as a function of previous information. Furthermore, comparing the MSW-GARCH models with others and arranging their performance in terms of suitability and predicting the out-of-sample volatility to test their fit.

Moreover, several directions (not included in this study) could be explored to improve the forecasts of the volatility of financial time series. for example, "true volatility" could be better estimated by selecting shorter time intervals. Hence, this study promises to study volatility persistence in more detail to improve volatility forecasts even further.

\section{Appendix}

Table A1. The results of models ARIMA (2, 1, 3), ARIMA $(3,1,3)$ and ARIMA $(2,1,1)$ for the three periods, respectively.

$$
\begin{aligned}
& \Phi_{2}(L) \Delta \ln p_{t}=\Theta_{3}(L) \varepsilon_{t} \\
& \left(1-\varphi L-\varphi_{2} L^{2}\right)(1-L) \ln p_{t}=\left(1+\theta L+\theta_{2} L^{2}+\theta_{3} L^{3}\right) \varepsilon_{t}
\end{aligned}
$$

EGX30

\begin{tabular}{lllll}
\hline Parameter & Coefficient & Std. Error & t-Statistic & P-Value \\
\hline Mean Equation & & & & 1.781851 \\
\hline$C$ & 0.00057 & 0.00032 & 44.49642 & 0.0748 \\
$\varphi_{1}$ & 1.465447 & 0.032934 & -30.30623 & 0.0000 \\
$\varphi_{2}$ & -0.913984 & 0.030158 & -38.44195 & 0.0000 \\
$\theta_{1}$ & -1.391852 & 0.036207 & 24.16893 & 0.0000 \\
$\theta_{2}$ & 0.829612 & 0.034326 & 3.824089 & 0.0000 \\
$\theta_{3}$ & 0.062865 & $1.64 \mathrm{E}-02$ & & 0.0001 \\
Akaike info criterion & -5.102557 & & & \\
Log likelihood & 11065.79 & & & \\
R-squared & 0.011473 & & & \\
Adjusted R-squared & 0.010331 & & & \\
S. E. of regression & 0.018856 & & & \\
\hline
\end{tabular}

$\Phi_{3}(L) \Delta \ln p_{t}=\Theta_{3}(L) \varepsilon_{t}$

$\left(1-\varphi L-\varphi_{2} L^{2}-\varphi_{3} L^{3}\right)(1-L) \ln p_{t}=\left(1+\theta L+\theta_{2} L^{2}+\theta_{3} L^{3}\right) \varepsilon_{t}$

Before

\begin{tabular}{lllll}
\hline Parameter & Coefficient & Std. Error & t-Statistic & P-Value \\
\hline Mean Equation & & & & 0.1131 \\
\hline & 0.001614 & 0.001018 & 1.585259 & 0.0000 \\
$\varphi_{1}$ & 0.490746 & 0.005069 & 96.81734 & 0.0000 \\
$\varphi_{2}$ & -0.489025 & 0.005599 & -87.33686 & 0.0000 \\
$\varphi_{3}$ & 0.991266 & 0.005054 & 196.1502 & \\
\hline
\end{tabular}




\begin{tabular}{lllll}
\hline Parameter & Coefficient & Std. Error & t-Statistic & P-Value \\
\hline Mean Equation & & & & 0.0000 \\
\hline$\theta_{1}$ & -0.49435 & 0.007793 & -63.43672 & 0.0000 \\
$\theta_{2}$ & 0.487147 & 0.008433 & 57.76597 & 0.0000 \\
$\theta_{3}$ & -0.979877 & $7.80 \mathrm{E}-03$ & -125.6206 & \\
Akaike info criterion & -4.964508 & & & \\
Log likelihood & 5271.861 & & & \\
R-squared & 0.013484 & & & \\
Adjusted R-squared & 0.010684 & & & \\
S. E. of regression & 0.020185 & & & \\
\hline
\end{tabular}

$\Phi_{2}(L) \Delta \ln p_{t}=\Theta_{1}(L) \varepsilon_{t}$

$\left(1-\varphi L-\varphi_{2} L^{2}\right)(1-L) \ln p_{t}=(1+\theta L) \varepsilon_{t}$

After

\begin{tabular}{lllll}
\hline Parameter & Coefficient & Std. Error & t-Statistic & P-Value \\
\hline Mean Equation & & & & 0.4928 \\
\hline$C$ & 0.000308 & 0.000449 & 0.686022 & 0.0000 \\
$\varphi_{1}$ & -0.576555 & 0.078361 & -7.357662 & 0.0000 \\
$\varphi_{2}$ & 0.134988 & 0.026512 & 5.091655 & 0.0000 \\
$\theta_{1}$ & 0.783694 & $7.56 \mathrm{E}-02$ & 10.3699 & \\
Akaike info criterion & -5.301409 & & & \\
Log likelihood & 5862.057 & & & \\
R-squared & 0.049015 & & & \\
Adjusted R-squared & 0.047722 & & & \\
S. E. of regression & 0.017068 & & & \\
\hline
\end{tabular}

Table A2. The final results of estimating GARCH models according to different distributions.

EGX30

\begin{tabular}{|c|c|c|c|c|c|c|}
\hline Mean Equation & & \multicolumn{5}{|c|}{$\Phi_{2}(L) \Delta \ln p_{t}=\Theta_{3}(L) \varepsilon_{t}$} \\
\hline ARIMA $(2,1,3)$ & & \multicolumn{5}{|c|}{$\left(1-\varphi L-\varphi_{2} L^{2}\right)(1-L) \ln p_{t}=\left(1+\theta L+\theta_{2} L^{2}+\theta_{3} L^{3}\right) \varepsilon_{t}$} \\
\hline \multicolumn{7}{|l|}{ Variance Equations } \\
\hline \multirow[t]{3}{*}{$\operatorname{GARCH}(1,1)$} & $\begin{array}{l}\text { Student's t } \\
\text { GED }\end{array}$ & \multicolumn{5}{|c|}{$\mathrm{GARCH}=\mathrm{C}(7)+\mathrm{C}(8)^{*} \operatorname{RESID}(-1)^{\wedge} 2+\mathrm{C}(9)^{*} \operatorname{GARCH}(-1)$} \\
\hline & & \multicolumn{5}{|c|}{$h_{t}=\omega+\alpha_{1} \varepsilon_{t-1}^{2}+\beta_{1} h_{t-1}$} \\
\hline & & \multicolumn{5}{|c|}{ Where $h_{t}=\sigma_{t}^{2}$} \\
\hline \multirow[t]{3}{*}{ EGARCH $(1,1)$} & $\begin{array}{l}\text { Student's t } \\
\text { GED }\end{array}$ & \multirow{2}{*}{\multicolumn{5}{|c|}{$\begin{array}{l}\mathrm{LOG}(\mathrm{GARCH})=\mathrm{C}(7)+\mathrm{C}(8) * \mathrm{ABS}(\mathrm{RESID}(-1) / @ \mathrm{SQRT}(\mathrm{GARCH}(-1)))+\mathrm{C}(9) * \mathrm{RESID}(-1) / @ \mathrm{SQRT}(\mathrm{GARCH}(- \\
1))+\mathrm{C}(10) * \mathrm{LOG}(\mathrm{GARCH}(-1)) \\
\ln \left(h_{t}\right)=\omega+\alpha_{1}\left|z_{t-1}\right|+\gamma_{1}\left(z_{t-1}\right)+\beta_{1} \ln \left(h_{t-1}\right)\end{array}$}} \\
\hline & & & & & & \\
\hline & & \multicolumn{5}{|c|}{ Where $z_{t-1}=\frac{\varepsilon_{t-1}}{\sigma_{t-1}}$} \\
\hline \multirow[t]{6}{*}{ TGARCH $(1,1)$} & $\begin{array}{l}\text { Student's t } \\
\text { GED }\end{array}$ & \multirow{3}{*}{\multicolumn{5}{|c|}{$\begin{array}{l}\operatorname{GARCH}=\mathrm{C}(7)+\mathrm{C}(8)^{*} \operatorname{RESID}(-1)^{\wedge} 2+\mathrm{C}(9) * \operatorname{RESID}(-1)^{\wedge} 2 *(\operatorname{RESID}(-1)<0)+\mathrm{C}(10)^{*} \operatorname{GARCH}(-1) \\
h_{t}=\omega+\alpha_{1} \varepsilon_{t-1}^{2}+\gamma_{1} \varepsilon_{t-1}^{2} I_{\left\{\varepsilon_{t-1}\right.}\langle 0\} \\
\text { Where }{ }{ }_{\left\{\varepsilon_{t}\langle 0\}\right.} h_{t-1}=1 \text { if } \varepsilon_{t}<0 \text {, and } 0 \text { otherwise }\end{array}$}} \\
\hline & & & & & & \\
\hline & & & & & & \\
\hline & GARCH & & EGARCH & & TGARCH & \\
\hline & Distributions & & Distributior & & Distribution & \\
\hline & Student's t & GED & Student's t & GED & Student's t & GED \\
\hline Mean Equation & & & & & & \\
\hline$C$ & 0.001106 & 0.000966 & 0.000843 & 0.000834 & 0.000912 & 0.000859 \\
\hline P-Value & 0.00000 & 0.00000 & 0.00020 & 0.00010 & 0.00010 & 0.00010 \\
\hline$\varphi_{1}$ & 1.26145 & 0.277041 & -0.438553 & -0.421623 & 1.256228 & 0.272408 \\
\hline P-Value & 0.00000 & 0.00000 & 0.00000 & 0.00000 & 0.00000 & 0.00000 \\
\hline$\varphi_{2}$ & -0.880473 & -0.96562 & -0.775267 & -0.758614 & -0.85622 & -0.957798 \\
\hline P-Value & 0.00000 & 0.00000 & 0.00000 & 0.00000 & 0.00000 & 0.00000 \\
\hline$\theta_{1}$ & -1.082579 & -0.09373 & 0.618713 & 0.603607 & -1.075696 & -0.088071 \\
\hline
\end{tabular}




\begin{tabular}{lllllll}
\hline & GARCH & & EGARCH & & TGARCH \\
\cline { 2 - 7 } & Distributions & & Distributions & & Distributions \\
\cline { 2 - 7 } & Student's t & GED & Student's t & GED & Student's t & GED \\
\hline P-Value & 0.00000 & 0.00000 & 0.00000 & 0.00000 & 0.00000 & 0.00010 \\
$\theta_{2}$ & 0.660611 & 0.915823 & 0.840817 & 0.823933 & 0.637724 & 0.908410 \\
P-Value & 0.00000 & 0.00000 & 0.00000 & 0.00000 & 0.00000 & 0.00000 \\
$\theta_{3}$ & 0.172337 & 0.18559 & 0.134265 & 0.133475 & 0.17076 & 0.186447 \\
P-Value & 0.00000 & 0.00000 & 0.00000 & 0.00000 & 0.00000 & 0.00000 \\
Variance Equation & & & & & \\
$\omega$ & 0.000016 & 0.000014 & -0.743927 & -0.699777 & 0.000018 & 0.000015 \\
P-Value & 0.00000 & 0.00000 & 0.00000 & 0.00000 & 0.00000 & 0.00000 \\
$\alpha 1$ & 0.197982 & 0.190382 & 0.317343 & 0.315979 & 0.143175 & 0.155070 \\
P-Value & 0.00000 & 0.00000 & 0.00000 & 0.00000 & 0.00000 & 0.00000 \\
$\gamma$ & & & -0.058742 & -0.045232 & 0.114251 & 0.076547 \\
P-Value & & & 0.00000 & 0.00100 & 0.00010 & 0.00800 \\
$\beta_{1}$ & 0.765715 & 0.782085 & 0.93931 & 0.944085 & 0.754053 & 0.774307 \\
P-Value & 0.00000 & 0.00000 & 0.00000 & 0.00000 & 0.00000 & 0.00000 \\
$\alpha+\beta$ & 0.963697 & 0.972467 & 1.256653 & 1.260064 & 0.897228 & 0.929377 \\
Log Likelihood & 12095.14 & 12047.59 & 12124.99 & 12069.45 & 12103.74 & 12051.57 \\
Akaike info criterion & -5.575612 & -5.553676 & -5.588923 & -5.563300 & -5.57912 & -5.555051 \\
Schwarz criterion & -5.560908 & -5.538971 & -5.572748 & -5.547125 & -5.562945 & -5.538876 \\
Hannan-Quinn criter. & -5.570421 & -5.548484 & -5.583213 & -5.557589 & -5.573409 & -5.549341 \\
Adjusted R-squared & -0.003041 & -0.004890 & -0.004414 & -0.004788 & -0.002638 & -0.005010 \\
\hline & & & & & &
\end{tabular}

Before

\begin{tabular}{|c|c|c|}
\hline Mean Equation & & $\Phi_{3}(L) \Delta \ln p_{t}=\Theta_{3}(L) \varepsilon_{t}$ \\
\hline $\operatorname{ARIMA}(3,1,3)$ & & $\left(1-\varphi L-\varphi_{2} L^{2}-\varphi_{3} L^{3}\right)(1-L) \ln p_{t}=\left(1+\theta L+\theta_{2} L^{2}+\theta_{3} L^{3}\right) \varepsilon_{t}$ \\
\hline $\begin{array}{l}\text { Variance Equations } \\
\text { GARCH }(1,1)\end{array}$ & Normal & $\begin{array}{l}\mathrm{GARCH}=\mathrm{C}(8)+\mathrm{C}(9) * \operatorname{RESID}(-1)^{\wedge} 2+\mathrm{C}(10)^{*} \operatorname{GARCH}(-1) \\
h_{t}=\omega+\alpha_{1} \varepsilon_{t-1}^{2}+\beta_{1} h_{t-1} \\
\text { Where } h_{t}=\sigma_{t}^{2}\end{array}$ \\
\hline EGARCH $(1,1)$ & GED & $\begin{array}{l}\mathrm{LOG}(\mathrm{GARCH})=\mathrm{C}(8)+\mathrm{C}(9) * \operatorname{ABS}(\operatorname{RESID}(-1) / @ \operatorname{SQRT}(\operatorname{GARCH}(-1)))+\mathrm{C}(10) * \operatorname{RESID}(- \\
\text { 1)/@SQRT(GARCH(-1)) + C(11)*LOG(GARCH(-1)) }\end{array}$ \\
\hline TGARCH $(1,1)$ & Normal & $\begin{array}{l}\ln \left(h_{t}\right)=\omega+\alpha_{1}\left|z_{t-1}\right|+\gamma_{1}\left(z_{t-1}\right)+\beta_{1} \ln \left(h_{t-1}\right) \\
\text { Where } z_{t-1}=\frac{\varepsilon_{t-1}}{\sigma_{t-1}} \\
\text { GARCH }=\mathrm{C}(8)+\mathrm{C}(9) * \operatorname{RESID}(-1)^{\wedge} 2+\mathrm{C}(10) * \operatorname{RESID}(-1)^{\wedge} 2 *(\operatorname{RESID}(-1)<0)+\mathrm{C}(11) * \operatorname{GARCH}(-1) \\
h_{t}=\omega+\alpha_{1} \varepsilon_{t-1}^{2}+\gamma_{1} \varepsilon_{t-1}^{2} I_{\left\{\varepsilon_{t-1}\langle 0\}\right.}+\beta_{1} h_{t-1} \\
\text { Where } I_{\left\{\varepsilon_{t}\langle 0\}\right.}=1 \text { if } \varepsilon_{t}<0 \text {, and } 0 \text { otherwise }\end{array}$ \\
\hline
\end{tabular}

\begin{tabular}{llll}
\hline & & & \\
\cline { 2 - 4 } & GARCH & EGARCH & TGARCH \\
\cline { 2 - 4 } & Distribution & Distributions & Distributions \\
\hline Mean Equation & & GED & Normal \\
$C$ & 0.000781 & 0.001791 & 0.000983 \\
P-Value & 0.0342 & 0.02470 & 0.05850 \\
$\varphi_{1}$ & -0.141939 & 0.431413 & 0.952157 \\
P-Value & 0.0309 & 0.00000 & 0.00000 \\
$\varphi_{2}$ & -0.765784 & 0.469095 & 0.295255 \\
P-Value & 0.00000 & 0.00000 & 0.00010 \\
$\varphi_{3}$ & -0.479022 & 0.095440 & -0.250073 \\
P-Value & 0.00180 & 0.00000 & 0.00030 \\
$\theta_{1}$ & 0.352876 & -0.282127 & -0.700292 \\
P-Value & 0.00000 & 0.00000 & 0.00000 \\
$\theta_{2}$ & 0.724906 & -0.551987 & -0.508393 \\
P-Value & 0.00000 & 0.00000 & 0.00000 \\
$\theta_{3}$ & 0.684393 & -0.158541 & 0.210295 \\
\hline
\end{tabular}




\begin{tabular}{|c|c|c|c|c|c|}
\hline & & \multicolumn{2}{|c|}{ GARCH } & EGARCH & TGARCH \\
\hline & & \multicolumn{2}{|c|}{ Distribution } & Distributions & Distributions \\
\hline & & \multicolumn{2}{|c|}{ Normal } & GED & Normal \\
\hline P-Value & & \multicolumn{2}{|c|}{0.00130} & 0.00000 & 0.00090 \\
\hline \multicolumn{2}{|l|}{$\begin{array}{l}\text { Variance Equation } \\
\omega\end{array}$} & \multicolumn{2}{|c|}{0.000010} & -0.620410 & 0.000004 \\
\hline \multicolumn{2}{|l|}{ P-Value } & \multicolumn{2}{|c|}{0.00000} & 0.00000 & 0.00000 \\
\hline \multicolumn{2}{|l|}{$\alpha_{1}$} & \multicolumn{2}{|c|}{0.230589} & 0.295677 & 0.148970 \\
\hline \multirow{2}{*}{\multicolumn{2}{|c|}{$\begin{array}{l}\text { P-Value } \\
\gamma\end{array}$}} & \multicolumn{2}{|c|}{0.00000} & 0.00000 & 0.00000 \\
\hline & & & & -0.007863 & -0.114199 \\
\hline \multicolumn{2}{|l|}{ P-Value } & \multirow{2}{*}{\multicolumn{2}{|c|}{078774}} & 0.70190 & 0.00000 \\
\hline \multicolumn{2}{|l|}{$\beta_{1}$} & & 0.787741 & 0.951185 & 0.905532 \\
\hline & \multicolumn{2}{|c|}{0.00000} & 0.00000 & 0.00000 \\
\hline \multicolumn{2}{|l|}{$\alpha+\beta$} & \multicolumn{2}{|c|}{1.018330} & 1.246862 & 1.054502 \\
\hline \multicolumn{2}{|c|}{ Log Likelihood } & \multicolumn{2}{|c|}{5654.658} & 5850.578 & 5624.754 \\
\hline \multicolumn{2}{|c|}{ Akaike info criterion } & \multicolumn{2}{|c|}{-5.322638} & -5.505496 & -5.293497 \\
\hline \multicolumn{2}{|c|}{ Schwarz criterion } & \multicolumn{2}{|c|}{-5.295954} & -5.473475 & -5.264145 \\
\hline \multicolumn{2}{|c|}{ Hannan-Quinn criter. } & \multicolumn{2}{|c|}{-5.312869} & -5.493773 & -5.282752 \\
\hline \multicolumn{2}{|c|}{ Adjusted R-squared } & \multicolumn{2}{|c|}{-0.090811} & -0.025679 & -0.077398 \\
\hline After & & & & & \\
\hline Mean Equation & & & $\Phi_{2}($ & $(L) \varepsilon_{t}$ & \\
\hline ARIMA $(2,1,1)$ & & & $(1-4$ & $L) \ln p_{t}=(1+\theta$ & \\
\hline Variance Equatior & & & & & \\
\hline $\operatorname{GARCH}(1,1)$ & & $\begin{array}{l}\text { nal } \\
\text { lent's t }\end{array}$ & GAR & $(6)^{*} \operatorname{RESID}(-1)^{\wedge}$ & \\
\hline & & & $h_{t}=c$ & & \\
\hline & & & Wher & & \\
\hline EGARCH $(2,2)$ & & & $\begin{array}{l}\mathrm{LOG} \\
2)))+\end{array}$ & $\begin{array}{l}5)+\mathrm{C}(6) * \mathrm{ABS} \\
-1) / @ \mathrm{SQRT}(\mathrm{GA}\end{array}$ & $\begin{array}{l}(-1)))+\mathrm{C}(7) * \operatorname{ABS}(\operatorname{RESID}(-2) / @ \operatorname{SQRT}(\mathrm{GARCH}(- \\
\mathrm{H}(-1))+\mathrm{C}(10) * \operatorname{LOG}(\operatorname{GARCH}(-2))\end{array}$ \\
\hline & & & $\ln \left(h_{t}\right.$ & $1\left|+\alpha_{2}\right| z_{t-2}|+\rangle$ & \\
\hline EGARCH $(1,1)$ & & lent's t & $\begin{array}{l}\text { LOG } \\
\mathrm{C}(8)^{*}\end{array}$ & $\begin{array}{l}5)+\mathrm{C}(6) * \mathrm{ABS} \\
(-1))\end{array}$ & $(-1)))+\mathrm{C}(7) * \operatorname{RESID}(-1) / @ \operatorname{SQRT}(\operatorname{GARCH}(-1))+$ \\
\hline & & & $\ln \left(h_{t}\right.$ & $\mid+\gamma_{1}\left(z_{t-1}\right)+\beta_{1}$ & \\
\hline & & & Wher & & \\
\hline TGARCH $(1,1)$ & & $\begin{array}{l}\text { nal } \\
\text { lent's t }\end{array}$ & GARC & $(6)^{*} \operatorname{RESID}(-1)^{\wedge}$ & $\mathrm{D}(-1)<0)+\mathrm{C}(8) * \operatorname{GARCH}(-1)$ \\
\hline & & & $h_{t}=c$ & ${ }_{-1}^{2} I_{\left\{\varepsilon_{t-1}\right.}\langle 0\}+\beta_{1}$ & \\
\hline & & & Wher & $\varepsilon_{t}<0$, and 0 & \\
\hline
\end{tabular}

\begin{tabular}{llllllll}
\hline & \multicolumn{9}{l}{ GARCH } & \multicolumn{3}{c}{ EGARCH } & & TGARCH \\
\cline { 2 - 7 } & Distributions & & Distributions & & Distributions \\
\cline { 2 - 7 } & Normal & Student's t & Normal & Student's t & GED & Normal & Student's t \\
\hline Mean Equation & & & & & & & \\
$C$ & 0.000930 & 0.001142 & 0.000379 & 0.000682 & 0.000726 & 0.000438 & 0.000816 \\
P-Value & 0.01430 & 0.00040 & 0.32170 & 0.03450 & 0.02240 & 0.25360 & 0.01200 \\
$\varphi_{1}$ & -0.788299 & -0.463981 & -0.693387 & -0.455991 & -0.802141 & -0.775475 & -0.451793 \\
P-Value & 0.00000 & 0.00020 & 0.00000 & 0.00010 & 0.00000 & 0.00000 & 0.00010 \\
$\varphi_{2}$ & 0.206103 & 0.088740 & 0.189313 & 0.088108 & 0.190106 & 0.215350 & 0.090525 \\
P-Value & 0.00000 & 0.00880 & 0.00000 & 0.00690 & 0.00000 & 0.00000 & 0.00650 \\
$\theta_{1}$ & 0.997803 & 0.654608 & 0.916511 & 0.657139 & 0.996321 & 0.996284 & 0.652009 \\
P-Value & 0.00000 & 0.00000 & 0.00000 & 0.00000 & 0.00000 & 0.00000 & 0.00000 \\
Variance Equation & & & & & & & \\
$\omega$ & 0.000011 & 0.000015 & -0.966273 & -0.692438 & -0.613285 & 0.000011 & 0.000016 \\
P-Value & 0.00000 & 0.00000 & 0.00000 & 0.00000 & 0.00000 & 0.00000 & 0.00000 \\
$\alpha_{1}$ & 0.161166 & 0.166711 & 0.247325 & 0.264860 & 0.253255 & 0.077957 & 0.080218 \\
P-Value & 0.00000 & 0.00000 & 0.00000 & 0.00000 & 0.00000 & 0.00000 & 0.00010 \\
\hline
\end{tabular}




\begin{tabular}{|c|c|c|c|c|c|c|c|}
\hline & \multirow{2}{*}{$\begin{array}{l}\text { GARCH } \\
\text { Distributions } \\
\end{array}$} & & \multicolumn{3}{|l|}{ EGARCH } & \multicolumn{2}{|l|}{ TGARCH } \\
\hline & & & Distributi & & & Distributi & \\
\hline & Normal & Student's t & Normal & Student's t & GED & Normal & Student's t \\
\hline$\gamma$ & & & 0.185809 & -0.098585 & -0.090552 & 0.144228 & 0.158034 \\
\hline P-Value & & & 0.00000 & 0.00000 & 0.00000 & 0.00000 & 0.00000 \\
\hline$\alpha_{2}$ & & & -0.152839 & & & & \\
\hline P-Value & & & 0.00000 & & & & \\
\hline$\beta_{1}$ & 0.806889 & 0.786401 & 0.303079 & 0.941654 & 0.950232 & 0.812447 & 0.781615 \\
\hline P-Value & 0.00000 & 0.00000 & 0.00080 & 0.00000 & 0.00000 & 0.00000 & 0.00000 \\
\hline$\beta_{2}$ & & & 0.620964 & & & & \\
\hline P-Value & & & 0.00000 & & & & \\
\hline$\alpha+\beta$ & 0.968055 & 0.953112 & 1.357177 & 1.206514 & 1.203487 & 0.890404 & 0.861833 \\
\hline Log Likelihood & 6148.169 & 6231.994 & 6165.723 & 6243.65 & 6228.228 & 6166.737 & 6243.638 \\
\hline Akaike info criterion & -5.557619 & -5.632574 & -5.570790 & -5.642217 & -5.628261 & -5.573518 & -5.642207 \\
\hline Schwarz criterion & -5.539562 & -5.611937 & -5.544995 & -5.619001 & -5.605045 & -5.552882 & -5.618991 \\
\hline Hannan-Quinn criter. & -5.551022 & -5.625035 & -5.561367 & -5.633736 & -5.619779 & -5.565979 & -5.633725 \\
\hline Adjusted R-squared & 0.035381 & 0.044397 & 0.042731 & 0.045620 & 0.036158 & 0.035890 & 0.045444 \\
\hline
\end{tabular}

Table A3. The estimate results for the Markov Switching model assuming EGARC (1,1) GED in the first regime and TGARCH (1,1) $N$ in the second.

\begin{tabular}{llll}
\hline Parameter & Estimate & Std. Error & $\operatorname{Pr}(>|\mathbf{t}|)$ \\
\hline Mean Equation & -0.4685 & 0.0802 & 0.000000 \\
$\alpha_{01}$ & 0.2519 & 0.0263 & 0.000000 \\
$\alpha_{11}$ & -0.0602 & 0.0111 & 0.000000 \\
$\alpha_{21}$ & 0.9452 & 0.0095 & 0.000000 \\
$\beta_{1}$ & 1.5200 & 0.0558 & 0.000000 \\
$\gamma_{1}$ & 0.0736 & 0.0131 & 0.000000 \\
$\alpha_{02}$ & 0.5724 & 0.4051 & 0.000000 \\
$\alpha_{12}$ & 0.0002 & 0.0000 & 0.078830 \\
$\alpha_{22}$ & 0.0006 & 0.0000 & 0.000000 \\
$\beta_{2}$ & 0.9931 & 0.0868 & 0.000000 \\
$p_{11}$ & 0.5749 & 0.0034 & 0.000000 \\
$p_{22}$ & $\mathrm{t}+1 \mid \mathrm{k}=1$ & $\mathrm{t}+1 \mid \mathrm{k}=2$ & \\
Transition matrix: & 0.9931 & 0.0069 & \\
$\mathrm{t} \mid \mathrm{k}=1$ & 0.5749 & 0.4251 & \\
$\mathrm{t} \mid \mathrm{k}=2$ & State 1 & 0.0118 & \\
Stable probabilities: & 0.9882 & & \\
& -24081.8432 & & \\
AIC & 12051.9216 & & \\
LL & -24011.7188 & & \\
BIC & & & \\
\hline
\end{tabular}

\section{References}

[1] ARNERIĆ, J., \& ERJAVEC, N. (2010). Regime Switching Modelling of Structural Changes Caused by Financial Crisis. Univ. of Zagreb, Faculty of Economics and Business, 492500 .

[2] Bollerslev, T. (1986). Generalized Autoregressive Conditional Heteroskedasticity. Journal of Econometrics, 31, 307-327.

[3] Brooks, C. (2008). Introductory Econometrics for Finance. Cambridge Univ. Press, Univ. of Reading, the ICMA Centre.

[4] Ding, Z., \& Granger, C. (1996). Modeling volatility persistence of speculative returns: a new approach. Journal of Econometrics, 73, 185-215.

[5] Ding, Z., Granger, C. W., \& Engle, R. F. (1993). Along Memory Property of Stock Market Returns and A New Model. Journal of Empirical finance, 1 (1), 83-106.

[6] Engle, R. (1982). Autoregressive conditional heteroscedasticity with estimates of the variance of United Kingdom inflation. Econometrica, 50, 987-1007.

[7] Engle, R. F., \& Ng, V. K. (1993). Measuring and Testing the Impact of News on Volatility. Journal of Finance, 48 (5), $1749-1778$.

[8] EViews 8 User's Guide (2013). Quantitative Micro Software, LLC.

[9] Franses, P. H., \& Dijk, D. v. (2003). Nonlinear Time Series Models in Empirical Finance. Cambridge: Cambridge University Press. 
[10] Franses, P. H., Dijk, D. v., \& Opschoor, A. (2014). Time Series Models for Business and Economic Forecasting. Cambridge: Cambridge University Press.

[11] Glosten, L. R., Jagannathan, R., \& Runkle, D. E. (1993). On the Relation between the Expected Value and the Volatility of the Nominal Excess Return on Stocks. Journal of Finance, 48 (5), 1779-1801.

[12] Gujarati, D. N. (2003). Basic Econometrics. West Point: United States Military Academy.

[13] Haas, M., Mittnik, S., \& Paolella, M. S. (2004). A New Approach to Markov-Switching GARCH Models. Journal of Financial Econometrics, 2 (4), 493-530.

[14] Hamilton, J. D. (1989). A new approach to the economic analysis of nonstationary time series subject to changes in regime. Econometrica, 57, 357-384.

[15] Henry, Ò. T. (2007). Between the Rock and a Hard Place: Regime Switching in the Relationship between Short-Term Interest Rates and Equity Returns in the UK. Univ. of Melbourne, Dept. of Economics, Research paper, 1019.

[16] Kestel, S. (2013). The Time Series Analysis. Albert-Ludwigs Univ. Freiburg, Department of Empirical Research and Econometrics.

[17] Klaassen, F. (1998). Improving GARCH volatility forecasts. Econometrics eJournal.

[18] (2002). Improving GARCH volatility forecasts with regime switching GARCH. Empirical Economics, 27, 363-394.

[19] Naeini, M. N., \& Fatahi, S. (2012). Regime Switching GARCH Models and GARCH Models, in Stock Market of the
Developing Countries. Razi Univ., Agricultural College, Master in economics.

[20] Nelson, D. B. (1991). Conditional Heteroscedasticity in Asset Return: A New Approach. Econometrica, 59 (2), 347-370.

[21] Pagan, A. R., \& Schwert, G. W. (1990). Alternative Models for Conditional Stock Volatility. Journal of Econometrics, 45, 267-290.

[22] Peters, J.-P. (2001). Estimating and Forecasting Volatility of Stock Indices Using Asymmetric GARCH Models and (Skewed) Student-t Densities. Univ. of Li ege, Ecole d'Administration des Affaires, 31-54.

[23] Priestley, M. B. (1980). State-dependent models: a general approach to non-linear time series analysis. Journal of Time Series Analysis, 1, 47-71.

[24] Schwert, G. W. (1989). Tests for Unit Roots: A Monte Carlo Investigation. Journal of Business \& Economic Statistics, 7 (2), 147-159.

[25] Taylor, S. J. (1986). Modelling Financial Time Series. New York: John Wiley.

[26] Tnders, W. (2015). Applied Econometric Time Series. Hoboken, NJ: Wiley: John Wiley \& Sons.

[27] Tsay, R. S., \& Chen, R. (2019). Nonlinear Time Series Analysis. Hoboken, NJ: Wiley: Wiley Series in Probability and Statistics. John Wiley \& Sons. 